\title{
Análisis comparativo de los marcadores de compromiso en los comentarios sobre noticias digitales en España y Chile ${ }^{1}$
}

A contrastive analysis of the engagement markers used in comments on digital news in Spain and Chile

Número especial

- IV -

Apelación en el discurso digital

2018

\section{Patricio Moya Muñoz}

Universidad de Chile

Chile

\section{María Luisa Carrió-Pastor}

Universitat Politècnica de València

España

ONOMÁZEIN - Número especial IV: Apelación en el discurso digital (octubre de 2018): 26-48 DOI: 10.7764/onomazein.add.02

ISSN: 0718-5758

\section{(C) $\underset{\mathrm{BY}}{(\mathrm{NO}}$}

Patricio Moya Muñoz: Facultad de Ciencias Físicas y Matemáticas, Universidad de Chile.

| Correo electrónico: pmoyam@uchile.cl

María Luisa Carrió-Pastor: Departamento de Lingüística Aplicada, Universitat Politècnica de València, España

| Correo electrónico: Icarrio@upv.es 


\section{Resumen}

El propósito de esta investigación es analizar y comparar los marcadores de compromiso utilizados en los comentarios sobre las noticias de los periódicos digitales El País, publicado en España, y Emol, publicado en Chile, utilizados en dos ámbitos temáticos distintos, la política y los deportes. En este estudio los marcadores de compromiso han sido considerados como parte del modelo de análisis del metadiscurso interpersonal; es decir, son elementos que involucran explícitamente a los lectores, ya sea para captar su atención o incluirlos como participantes del discurso (Hyland, 2005a). Para su análisis, se recopiló un corpus compuesto de 2.400 comentarios digitales a noticias, que fueron etiquetados manualmente con la herramienta UAM Corpus Tool con el fin de identificar los mecanismos empleados como marcadores de compromiso. Los resultados señalaron que los comentaristas del diario Emol y los de El País utilizaron un número similar de marcadores de compromiso; por otro lado, tampoco identificamos variación significativa en el uso de estos marcadores en los dos ámbitos temáticos, aunque en ambos periódicos se utilizaron más en los comentarios sobre noticias políticas.

Palabras clave: marcadores de compromiso; metadiscurso; comentarios; noticias digitales; variedades del español.

\section{Abstract}

The purpose of this research is to determine and analyse the engagement markers used in the comments on the news published in the online papers El País (Spain) and Emol (Chile). The comments were selected from two different contexts: politics and sports. In this study we consider engagement markers as part of interactional metadiscourse, that is, the elements that involve readers to call their attention or to include them as participants of discourse (Hyland, 2005a). In this research, a corpus of 2,400 comments were compiled and tagged manually and with UAM Corpus Tool. The purpose of the analysis was to identify the metadiscoursal strategies used as engagement markers. The results showed that the writers that comment news in Emol and in El País used a similar amount of engagement markers; on the other hand, significative variation was not identified in the use of engagement markers in comments on politics and sports, although these markers were more frequently found in political comments.

Keywords: engagement markers; metadiscourse; comments; digital news; Spanish varieties.

$1 \quad$ Esta investigación forma parte del proyecto concedido por el Ministerio de Economía y Competitividad (España) en 2016 con referencia FFI2016-77941. 


\section{Introducción}

Uno de los factores que nos empujó a realizar esta investigación fue analizar el impacto de la tecnología en la sociedad actual y, por ende, los cambios lingüísticos que esto provoca, ya que ha incitado a un incipiente desarrollo de distintas formas de interacciones comunicativas. De manera paulatina, los medios masivos de comunicación, como lo es la prensa, se han ido adaptando a los requerimientos tecnológicos y sociales que ha impuesto la implantación de la Web 2.o. Ello se debe a que el uso de la tecnología ha significado un cambio radical en la forma en la que entendemos la práctica de la transmisión y difusión de la información de las noticias.

En este contexto, la participación de los lectores en distintos momentos de la producción periodística ha comenzado a jugar un rol fundamental, ya que el lector ha pasado de ser principalmente pasivo a desempeñar un papel activo, no solo en la difusión de la información, sino también en el intercambio de ideas (Cebrián Herreros, 2009; Ruiz, Masip, Micó, Díaz-Noci y Domingo, 2010; Meso, 2013). Específicamente, las redes sociales han facilitado dicha participación ciudadana en un núcleo de poder tan importante para la sociedad contemporánea como lo son las noticias, puesto que los lectores perciben las redes sociales como medios para interaccionar con la información (Martinrey y Serrano Marín, 2011). Según Cebrián Herreros (2009: 17), "Ios cibermedios alteran los modelos comunicativos al incorporar plenamente los procesos de interactividad de los emisores con los usuarios. La interactividad se instala como un proceso multidimensional”. De esta forma, comentar digitalmente las noticias se ha transformado en uno de los mecanismos habituales propuesto por los periódicos para aumentar la fidelización de los usuarios y reforzar el vínculo de pertenencia del lector con el mismo periódico (Ruiz, Domingo, Micó, Díaz-Noci, Meso y Masip, 2011; Pastor y Martínez-Martínez, 2013).

La importancia de este hecho, es decir, analizar las formas de participación de los lectores en la transmisión de la información, es lo que impulsó esta investigación. Consideramos que es necesario un estudio de las estrategias retóricas que utilizan los lectores para poder trazar nuevos patrones lingüísticos e identificar variaciones en el uso de una lengua. Por esta razón, nuestra hipótesis de partida fue que existe variación metadiscursiva en el uso del español, por hablantes que utilizan distintas variedades lingüísticas, al realizar comentarios digitales. El objetivo general de este artículo es identificar la variación en el uso de los marcadores de compromiso utilizados en los comentarios digitales sobre las noticias de los periódicos El País de España y Emol de Chile en los ámbitos de política y deportes. Por lo tanto, las preguntas de investigación que nos planteamos en este artículo son las siguientes:

a. ¿Utilizan los hablantes de distintas variedades del español distintos marcadores de compromiso? Concretamente, ¿cómo captan los comentaristas de noticias españoles y chilenos la atención de los lectores para incluirlos como participantes del discurso digital? 
b. ¿Cómo utilizan los hablantes de distintas variedades del español los marcadores de compromiso en los comentarios digitales sobre la política y los deportes?

Para responder estas preguntas de investigación, en primer lugar vamos a comentar los avances que se han realizado en los estudios sobre prensa digital y los marcadores de compromiso. A continuación, en segundo lugar, describiremos el método seguido en este análisis. En tercer lugar, detallaremos los resultados obtenidos y, finalmente, contestaremos las preguntas de esta investigación en el apartado de las conclusiones.

\section{Los comentarios en la prensa digital y los marcadores de compromiso}

Respecto a los comentarios sobre las noticias en la prensa, aunque pueda parecer un fenómeno reciente, la participación de los lectores en las noticias tiene una larga historia. Ya desde el siglo XVIII los diarios ingleses comúnmente dejaban espacios en blanco al final de la tercera página para los comentarios de los lectores; así, los lectores podían doblarla y enviar los comentarios como una carta ordinaria (Wiles, 1965), lo que permitía cierta interacción con las noticias que se publicaban. Por ello, no consideramos que la interacción entre lector y noticia sea un fenómeno sin precedentes, ya que podemos rastrear comportamientos comunicativos similares (Thurlow y Mroczek, 2011; Mancera Rueda y Pano Alamán, 2013), pero sobre todo nos interesa este aspecto porque la comunicación mediada por computador incorpora nuevas formas de interacción. En este artículo analizamos de qué forma las características de los comentarios en la prensa digital, tales como el sentido de inmediatez, la invisibilidad del emisor y receptor, la capacidad de reflexión antes de participar y la comunicación asíncrona (a cualquier hora) y móvil (desde cualquier lugar), modifican las estrategias retóricas en una lengua.

Herring (2013) indica que los comentarios de noticias digitales corresponderían a un tipo de discurso denominado reconfigurado, ya que guardarían relación con los primeros foros de discusión, que datan de los inicios de la comunicación mediada por computador, pero que se han ido adaptando a los cambios tecnológicos. En relación con su clasificación como género discursivo, se han señalado diferentes aproximaciones (Moya Muñoz, 2015). Por un lado, Bruce (2011) entiende que los comentarios de noticias digitales no se pueden analizar separados de la noticia que los ha motivado, en la medida en que se trataría de un género híbrido compuesto llamado artículo de noticias participativo. Por otro lado, mientras algunos autores apuntan que se trata de un blog periodístico (González Arias y López, 2013; Arancibia y Montecino, 2013; González Arias, 2014; Montecino y Arancibia, 2015), otros comentan que se trata de un foro que se integra en los periódicos para que los usuarios puedan participar (Montero-Fleta, Montesinos-López, Pérez-Sabater y Turney, 2009; Mancera Rueda, 2009; Pano Alamán, 2012, 2013; Acebedo Restrepo, 2013). 
Sal Paz $(2013,2016)$ precisa que el género de comentarios de noticias es parte de un continuum de formas interactivas, que se relaciona con la conversación, la discusión, el debate o la disputa. Presenta dos tipos de funciones definidas. La primera es una forma de respuesta a la noticia de la que es parte (similar a lo planteado por Bruce, 2011), en la que el artículo noticioso resulta ser el estímulo para una posterior réplica, es decir, la realización del comentario, por lo que termina siendo muy difícil considerarlo como un género independiente de la noticia. La segunda función sería la de una respuesta que se integra en un conjunto de voces previas (Sal Paz, 2013: 158) que construyen un mundo discursivo, pasando de ser un comentario aislado a una conversación, aspecto que también comparte Pano Alamán (2013).

Varios son, pues, los estudios dedicados a los comentarios de noticias, pero ninguno analiza el uso de los marcadores de compromiso en dos variedades del español. Dada la importancia de los lectores/interlocutores en este tipo de comunicación, creemos que es importante analizar los marcadores de compromiso que se utilizan para marcar el territorio del escritor y llamar la atención del lector. En líneas generales, los estudios sobre el metadiscurso se han centrado, principalmente, en el análisis del discurso académico (Hyland y Tse, 2004; Hyland, 2005a; Mur-Dueñas, 2011; Li y Wharton, 2012; Alonso Almeida y Carrió-Pastor, 2015; Carrió-Pastor, 2016), aunque algunos investigadores también los han utilizado para estudiar otros géneros discursivos (Carrió-Pastor y Muñiz Calderón, 2013, 2015a, 2015b; González Arias, 2014). En este artículo hemos decidido centrarnos en el estudio de los marcadores de compromiso, ya que este tipo de estrategias son vitales para lograr que se lean los comentarios a noticias y se repliquen. Hyland (2005a) es uno de los máximos exponentes de los análisis metadiscursivos y considera los marcadores de compromiso como una categoría de las estrategias metadiscursivas interpersonales. Concretamente, Hyland y Tse (2004) definen los marcadores de compromiso como dispositivos que involucran explícitamente a los lectores, ya sea para captar su atención o para incluirlos como participantes del discurso. La función de los marcadores de compromiso la describe Hyland (2005a: 54) de la siguiente manera:

[El escritor] reconoce la necesidad de satisfacer adecuadamente las expectativas de inclusión y solidaridad disciplinaria de los lectores, abordándolas como participantes en una discusión con los pronombres lectores (tú, tu, nosotros inclusivo) [...]. El segundo objetivo consiste en posicionar retóricamente al público, atraer a los lectores al discurso en puntos críticos, predecir posibles objeciones y guiarlos hacia interpretaciones particulares. Estas funciones se realizan principalmente mediante preguntas, directivos (como el uso de imperativos, como ver, nota y considérese y verbos modales de obligación como deber, tener que, etc.) y referencias al conocimiento compartido.

A pesar de que existen investigaciones sobre los marcadores de compromiso como parte del análisis general de las estrategias metadiscursivas en diferentes géneros digitales (Herring y Demarest, 2011; Suau-Jiménez, 2014; González Arias, 2014), la mayor parte de los trabajos de esta área específica (como apuntábamos antes respecto a los estudios sobre el metadiscurso) se ha realizado en el ámbito del discurso académico (Mur-Dueñas, 2008; Taki y Jafarpour, 
2012; Lafuente-Millán, 2014; Hyland y Jiang, 2016; Peterlin, 2016). En este artículo consideramos que los marcadores de compromiso cumplen una función esencial para lograr una réplica interpersonal en los comentarios digitales, puesto que solicitan la respuesta de los lectores y, al mismo tiempo, logran su apoyo con respecto a las proposiciones que está planteando el escritor (Mur-Dueñas, 2008; Lafuente-Millán, 2014). En esta categoría se incluyen aquellos elementos a través de los cuales los escritores integran a los lectores dentro del texto, involucrándolos en la negociación del significado de las proposiciones (Mur-Dueñas, 2008). El rol que juega este tipo de marcadores es fundamental en la medida en que el escritor intenta anticiparse a posibles dificultades, lo que minimizaría el riesgo de que se produzca el rechazo de las aseveraciones. Al anticiparse a los conocimientos y expectativas de fondo de los interlocutores, un escritor puede llegar a monitorear las respuestas de los lectores (Hyland y Jiang, 2016).

Desde un punto de vista pragmático, el uso de los marcadores de compromiso puede cumplir diferentes propósitos interpersonales como el compromiso, la familiaridad, la cortesía, y, obviamente, trasmitir cierta actitud al lector que le guie hacia los objetivos que busca el escritor (Lafuente-Millán, 2014). Estos marcadores se refieren a todos aquellos casos que atraen a los lectores a leer el texto, involucrándolos en la negociación del significado pragmático que se desea conseguir (Mur-Dueñas, 2008), Ilamando su atención o, simplemente, incluyéndolos como participantes del discurso (Hyland, 2005a).

Los elementos que se consideran como marcadores de compromiso según Fu y Hyland (2014) son los pronombres personales dirigidos al lector, imperativos dirigidos al lector, los verbos modales de necesidad y obligación, las preguntas al lector y las palabras que implican un conocimiento compartido con el lector. Asimismo, su frecuencia estaría determinada por la relación entre el escritor y el lector que existe en un contexto genérico particular (Mur-Dueñas, 2008), variando según el tipo de contexto analizado (Hyland, 2005b; Abdollahzadeh, 2011; Mur-Dueñas, 2011; González Arias, 2014; Lafuente-Millán, 2014; Fu y Hyland, 2014; Jiang y Hyland, 2016; Hyland y Jiang, 2016). Por ello, y dado que los marcadores de compromiso en los comentarios digitales de noticias no han sido el centro de atención de ninguno de los estudios consultados, entendemos que es necesario un análisis y discusión de este tema para identificar las variaciones de la lengua española y de la comunicación en dos ámbitos distintos, es decir, la política y los deportes.

\section{El estudio}

\subsection{Corpus}

Para recopilar un corpus que nos permitiera el análisis de los comentarios digitales de noticias en periódicos, analizamos, en primer lugar, los periódicos que se publicaban en formato digital y seleccionamos los que más comentarios generaban, tanto en España como en Chile. Después de un análisis de los periódicos con un formato online, decidimos seleccionar los 
comentarios generados por noticias del periódico El País, publicado en España, y los comentarios a las noticias del periódico chileno Emol, puesto que eran los periódicos que suscitaban más comentarios por parte de sus lectores. Asimismo, los ámbitos seleccionados fueron la política y los deportes porque eran las temáticas con más comentarios.

En segundo lugar, el corpus se extrajo desde las plataformas que ambos periódicos utilizan para que los lectores puedan hacer comentarios. En el caso de Emol se utiliza Facebook para que los comentaristas puedan comentar y/o replicar a las noticias, y en el caso de El País, la plataforma que se pone a disposición de los comentaristas de noticias es Eskup. En ambas plataformas los usuarios se tienen que registrar para poder comentar sobre noticias. Las características de las dos plataformas son similares, permiten la inserción de textos, videos, imágenes, etc., pero en Eskup existe una limitación, ya que los mensajes pueden tener un máximo de 280 caracteres. De igual manera, tanto en Facebook como en Eskup existe la posibilidad de reportar comentarios que pudieran resultar ofensivos o groseros para la comunidad con el fin de que sean eliminados.

Finalmente, seleccionamos 1.200 comentarios realizados por comentaristas españoles sobre las noticias publicadas en El País y 1.200 comentarios realizados por comentaristas chilenos sobre las noticias publicadas en Emol. Se distinguieron las distintas procedencias por las variedades de la lengua y por las ciudades de procedencia de los autores de los comentarios. Aquellos comentarios en los que dudábamos sobre la procedencia de sus autores se eliminaron del corpus. Así pues, el corpus total está compuesto de 2.400 comentarios digitales sobre noticias. Del subcorpus de comentarios realizados por españoles en El País, se habían seleccionado 600 comentarios sobre política y 600 comentarios sobre deportes. Se procedió del mismo modo en el subcorpus de comentarios escritos por chilenos en Emol y se recopilaron 600 comentarios sobre política y otros 600 comentarios sobre deportes.

El corpus se seleccionó de forma manual entre 2012 y 2013, y las características detalladas del corpus recopilado se pueden observar en la tabla 1.

Los comentarios digitales sobre noticias que formaban parte del corpus no se alteraron, es decir, si los comentaristas escribían errores ortográficos o tipográficos no se corrigieron. Nuestro propósito era analizar un corpus real compuesto de comentarios digitales realizados por españoles y chilenos sobre política y deportes, y por ello mantuvimos sus características.

\subsection{Procedimiento del estudio}

Una vez recopilado el corpus para el estudio y dado que nuestra intención era llevar a cabo un estudio cuantitativo, el siguiente paso fue realizar una plantilla para su etiquetado. La plantilla se basó en las propuestas de Hyland (2005a), Mur-Dueñas (2008, 2011), Fu y Hyland 


\section{TABLA 1}

Corpus de comentarios digitales de El País y Emol

\begin{tabular}{llllll} 
& EL PAIS & \multicolumn{3}{c}{ EMOL } & TOTAL \\
\hline & Deportes & Política & Deportes & Política & \\
Número de comentarios & 600 & 600 & 600 & 600 & 2.400 \\
\hline Noticias empleadas & 30 & 25 & 26 & 26 & 107 \\
\hline $\begin{array}{l}\text { Longitud de comentarios } \\
\text { (rango de palabras) }\end{array}$ & $67-210$ & $73-211$ & $53-529$ & $58-563$ & $53-523$ \\
\hline $\begin{array}{l}\text { Longitud de comentarios } \\
\text { (promedio de palabras) }\end{array}$ & 118 & 123,9 & 122,2 & 125,3 & 123 \\
\hline Número total de palabras & 71.384 & 74.345 & 73.343 & 75.173 & 294.245 \\
\hline
\end{tabular}

(2014) y Hyland y Jiang (2016), e incluye las siguientes categorías de marcadores de compromiso: primera persona plural inclusiva (nosotros inclusivo, es decir, yo junto a un ustedes del que el yo es parte), segunda persona singular (tú), segunda persona plural (ustedes, en el caso de El País, se considera como segunda persona plural formal), segunda persona plural informal (vosotros, solo en el caso de El País), segunda persona singular formal (usted) y otras realizaciones (donde se incluye, por ejemplo, el uso de las preguntas retóricas). Dado que las categorías "primera persona plural inclusiva", "segunda persona singular" y "otras realizaciones" fueron las más frecuentes, cada una de ellas se desglosó para analizarlas en detalle. Respecto a la "primera persona plural inclusiva" y la "segunda persona singular", se analizaron por separado en ambas las subcategorías desinencia verbal, pronombre personal, adjetivo posesivo, pronombre posesivo y pronombre personal y desinencia verbal. En el caso de la categoría de "segunda persona singular", se incorporó además la subcategoría de voseo. En la categoría "otras realizaciones" se analizaron las categorías vocativo, pregunta retórica, despedida, petición, agradecimiento, "uno” genérico y saludos.

Esta taxonomía se utilizó para el etiquetado manual del corpus con la herramienta para el análisis UAM Corpus Tool (O’Donnell, 2013). Dadas las características de las estrategias metadiscursivas, por el momento no se dispone de una herramienta que automatice este proceso, con lo cual se utilizó la herramienta para anotar, no para analizar de forma automática el corpus, puesto que por ahora no existe esa posibilidad.

Después se identificaron y extrajeron todos los casos en sus dos contextos, la política y los deportes, en las dos variedades de la lengua, el español de España y el español de Chile. A continuación se copiaron los resultados en una hoja de cálculo para su posterior análisis. Cada caso fue analizado detalladamente, lo que permitió clasificarlos en diferentes categorías con el objetivo de sistematizar los resultados y sus posteriores interpretaciones. 
El cálculo de los casos que se encontraron de los marcadores de compromiso se realizó separadamente por periódico y ámbito temático para poder determinar sus diferencias. Para poder comparar los resultados encontrados en los dos subcorpus y dado que los dos subcorpus no tenían el mismo número de palabras, normalizamos las frecuencias que encontramos por 10.000 palabras. También calculamos la relevancia de los resultados totales mediante el test estadístico Chi-cuadrado.

Una vez extraídos los resultados, procedimos al análisis cuantitativo y a comentar los distintos marcadores de compromiso empleados mediante ejemplos del corpus analizado. Una vez comentadas y comparadas las tres subcategorías de marcadores de compromiso más frecuentemente utilizadas por los lectores de El País y Emol, procedimos a contrastar nuestra hipótesis y responder a los objetivos y preguntas de investigación de nuestro estudio en las conclusiones.

\section{Resultados y discusión}

Los casos de marcadores de compromiso detectados se pueden observar en la tabla 2. Con el fin de realizar una comparación objetiva de las muestras, las frecuencias se normalizaron por 10.000 palabras.

\begin{tabular}{|c|c|c|}
\hline SUBCORPUS & $\begin{array}{l}\text { CASOS DE MARCADORES } \\
\text { DE COMPROMISO }\end{array}$ & $\begin{array}{l}\text { FRECUENCIA NORMALIZADA } \\
\text { POR 10.000 PALABRAS }\end{array}$ \\
\hline El País deportes & 1.470 & 205,9 \\
\hline El País política & 1.853 & 249,2 \\
\hline Subtotal El País & 3.323 & 228,0 \\
\hline Emol deportes & 1.695 & 231,1 \\
\hline Emol política & 1.794 & 238,6 \\
\hline Subtotal Emol & 3.489 & 234,9 \\
\hline Total & 6.812 & 231,5 \\
\hline
\end{tabular}

Se puede apreciar que la frecuencia encontrada en los marcadores de compromiso en ambos periódicos es similar (228,0 en El País y 234,9 en Emol). Se calculó la prueba estadística Chi-cuadrado para identificar la relevancia de los datos encontrados y saber si se podían extrapolar a otros estudios similares. El resultado de Chi-cuadrado fue igual a 12,74. Los resultados son 
estadísticamente significativos ya que se acepta la hipótesis nula, pues el valor de Pasociado al resultado observado fue $<0,05$, que fue el nivel de significación establecido. El valor de P de los resultados fue igual a 0,0004 .

Si comparamos estos datos con los presentados en otras investigaciones, se puede observar que en este estudio detectamos más casos de marcadores de compromiso. Por ejemplo, en los estudios sobre discurso académico las frecuencias normalizadas a 10.000 que encontraron los investigadores son inferiores: Hyland (2005a) detectó 47,8 frecuencias; Mur-Dueñas (2011), 18,5, y Li y Wharton (2012), 84,7. Por otro lado, en el análisis de comentarios sobre columnas de opinión digitales, González Arias (2014) encontró 148,3 frecuencias normalizadas a 10.000, una cifra que es más elevada que las anteriores pero inferior a la detectada en este artículo. Esta diferencia con González Arias (2014) puede explicarse porque el autor no efectuó la diferenciación entre primera persona plural inclusiva y exclusiva, considerando ambos fenómenos como automenciones, mientras que en este artículo nos hemos basado en las distinciones de Hyland (2005a), Mur-Dueñas (2008, 2011), Fu y Hyland (2014) y Hyland y Jiang (2016), que incluyen los casos de primera persona plural inclusiva como marcadores de compromiso.

Hemos de destacar que se han encontrado más casos en los comentarios digitales de noticias que en el discurso académico y este hecho reafirma la idea de que el uso de los marcadores de compromiso está influido por el contexto situacional. El discurso que se construye en los comentarios de noticias podría incluso entenderse como parte de una construcción colectiva, en la que la relación e interacción con los demás usuarios se actualiza por medio de una serie de estrategias que buscan el compromiso, participación y apoyo de la información que envía el comentarista. Por el contrario, en el discurso académico, las referencias a la audiencia no son tan directas, dado que la audiencia es específica, ya que comparte la misma disciplina e intereses, pero, al mismo tiempo, también es muy amplia, ya que no existe un "tú" en concreto. En cambio, en los comentarios de noticias se busca el compromiso directo del lector y se necesitan más marcadores de compromiso.

Al mismo tiempo, si observamos la frecuencia de los marcadores de compromiso según el ámbito temático, los comentarios sobre noticias políticas son los que más frecuentemente los utilizan. Este hecho podría estar relacionado con el grado de afiliación que se buscaría en los comentarios de noticias políticas, en los que resulta más importante convencer al lector del tema que se está planteando.

Ahora bien, si observamos los casos encontrados de marcadores de compromiso, hemos de tener en cuenta que el sistema pronominal en español ofrece una variedad mucho más extensa de partículas que pueden ejercer esta función que las que podemos encontrar en la lengua inglesa. Asimismo, al analizar los casos encontrados, las diferentes variedades del español se han de tener en cuenta, puesto que, por ejemplo, en el español peninsular se emplea el pronombre "vosotros" para referirse a la segunda persona plural, mientras que "ustedes" se 
usa para marcar relaciones jerárquicas que implican formalidad; sin embargo, los hablantes latinoamericanos usan solo la forma "ustedes" para la segunda persona plural. Estas particularidades son las que provocaron que se analizaran los marcadores de compromiso en distintas categorías y las más frecuentes en subcategorías, como hemos explicado en el apartado sobre la metodología seguida en este estudio.

En la figura 1 se observan las frecuencias de las distintas categorías que hemos hallado y que actúan como marcadores de compromiso. Las estrategias más empleadas son, por orden de frecuencia, la primera persona plural inclusiva, la segunda persona singular y otras realizaciones o casos:

\section{FIGURA 1}

Gráfico de frecuencias de los marcadores de compromiso

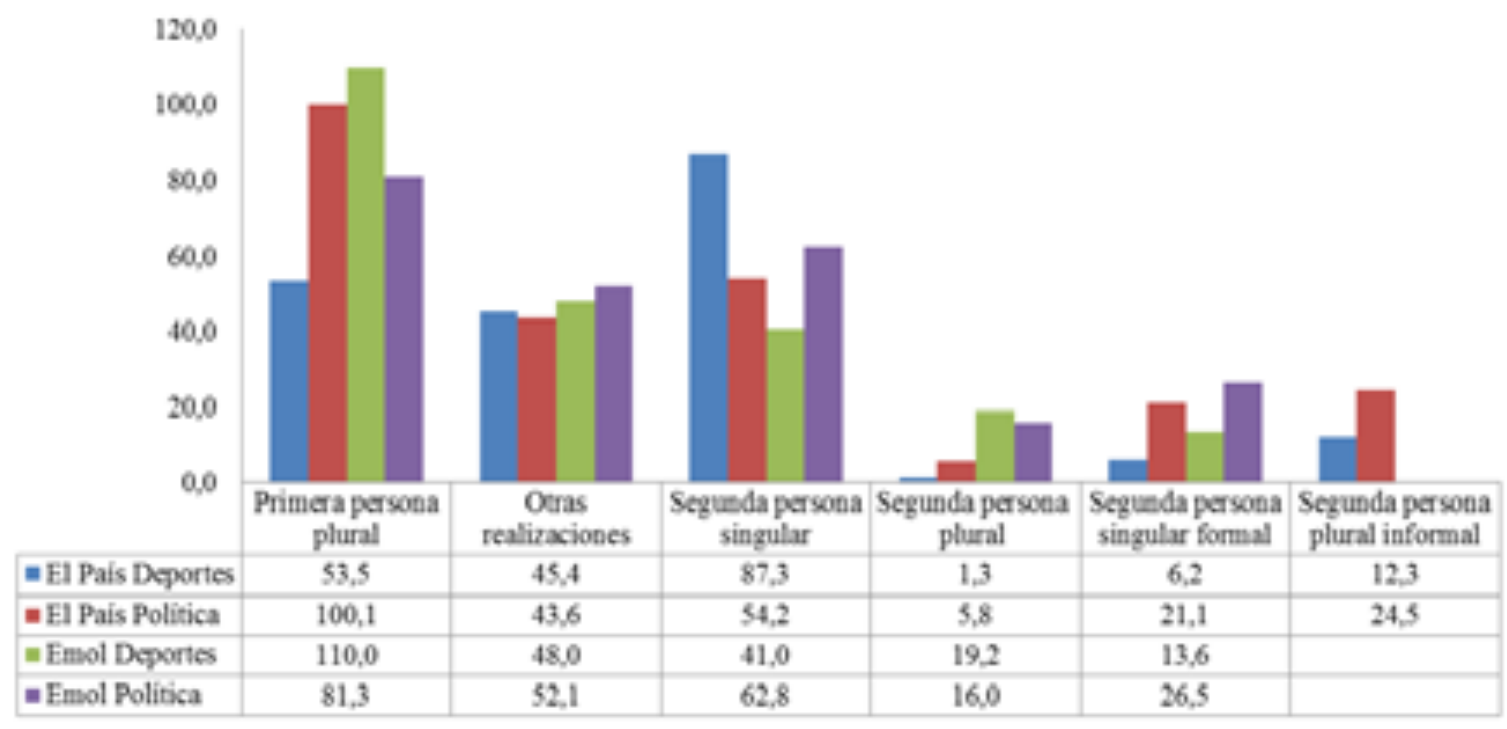

Se puede observar en la figura 1 que no hemos hallado una relación directa que unifique los resultados encontrados en los ámbitos temáticos de política y deportes, ya que se han encontrado datos dispares en los dos ámbitos según la categoría de marcadores de compromiso. Por ello, hemos considerado necesario analizar en detalle las tres categorías más frecuentes para precisar si existe o no variación en el uso de los marcadores.

En la figura 2 se pueden distinguir las frecuencias normalizadas a 10.000 de los casos de la primera persona plural inclusiva y de las subcategorías que analizamos y que se han explicado en la metodología.

La subcategoría más empleada como marcador de compromiso es la "desinencia verbal" (creemos), seguida del "pronombre personal” (nos). Además, es interesante destacar dos as- 


\section{FIGURA 2}

Gráfico de frecuencias de la primera persona plural inclusiva

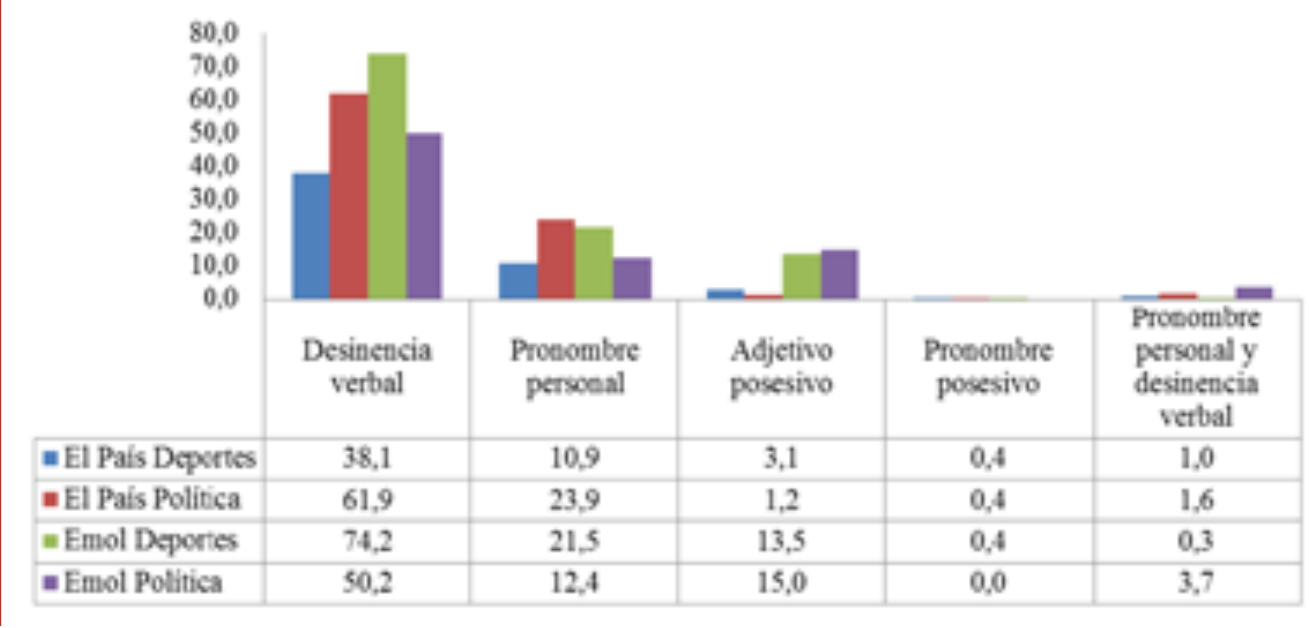

pectos; por un lado, en los subcorpus de Emol se ha detectado un uso más frecuente de los "adjetivos posesivos" que en El País y, por otro, destaca la baja frecuencia en el uso del "pronombre personal junto a la desinencia verbal" (nosotros creemos). Asimismo, es de destacar, como se ha apuntado en los resultados generales, que tampoco hemos hallado una variación en el uso de marcadores de compromiso causada por el ámbito temático.

La desinencia verbal transmite la intención de primera persona plural inclusiva y le permite al autor integrar a la audiencia en su contexto, con el fin de lograr adhesión respecto a su propósito comunicativo. Una de las peculiaridades de este uso radica en que el autor no alude directamente a su receptor, sino que lo incluye dentro de su discurso de una manera no directa y, por tanto, procurando mantener la imagen positiva de sus receptores, tal como se aprecia en los ejemplos (1) y (2):

(1) Creo que me recuerda algo este hecho. Todo un estadio de fútbol en el cual se celebra un evento deportivo es utilizado por la burguesía más reaccionaria para consumar un hecho político y es que se han dilapidado el dinero de los catalanes persiguiendo a los comerciantes que no rotulan en catalán y en la mal Ilamada inmersión o inversión o sabe Dios que. Siguen derrochando para discriminar a todo aquel hijo de vecino que no quiera hablar catalán vulnerando la constitución votada por una mayoría aplastante ya que de eso trata la democracia. En fin seguir subvencionando las embajadas que esto si que es importante y retrasar el pago de lo demás que así vamos bien. En fin no podemos pedirles peras al olmo. Espero que no me lo borréis (elpaís_dep_03_24).

En el ejemplo (1), el comentarista divide su discurso en las acciones que hacen "otros", mediante la forma impersonal "es utilizado", "se han dilapidado", "siguen derrochando", y las acciones en las que utiliza la primera persona plural inclusiva "vamos", "podemos". Con ello, 
intenta lograr la adhesión del lector mediante los marcadores de compromiso y traza una línea entre las distintas acciones: las malas (las que hacen los demás) y las buenas o reivindicativas (las que hacemos nosotros).

(2) A ver, vamos aclarando un poco. Estamos en Chile, un pais en vias de desarrollo y un Estado de Derecho. Esto no es Africa subsahariana. Tenemos libertad de prensa y de expresión, por lo que el señor Luchsinger puede dcir las cabezas de pescado que quiera y nadie le puede decir nada. Por lo mismo todos podemos escribir aqui. Los señores que cometieron el atentado mataron a dos personas, eso se llama asesinato, y tiene establecidas condenas en nuestro codigo penal. El tema es que ley pareja no es dura, y les guste o no a los mapuches estan en territorio chileno, tienen nacionalidad chilena, no son un estado araucano independiente, y deben ser juzgados con el mismo razero que cualquiera de nosotros. [...] (emol_pol_06_09).

En el ejemplo (2), el comentarista utiliza reiteradamente la primera persona inclusiva mediante la desinencia verbal "estamos" "tenemos" y el adjetivo posesivo "nuestro" para incluir al lector en su razonamiento, lo que le da más fuerza a su argumentación. Con esta estrategia pretende que su reivindicación sea plural tanto para el lector como para las personas que está denunciando, intensificando con los marcadores la complicidad con los lectores.

A continuación pasamos a detallar, en la figura 3, las frecuencias normalizadas a 10.000 de la segunda categoría más frecuente, la segunda persona singular:

\section{FIGURA 3}

Gráfico de frecuencia de uso de los casos de segunda persona singular

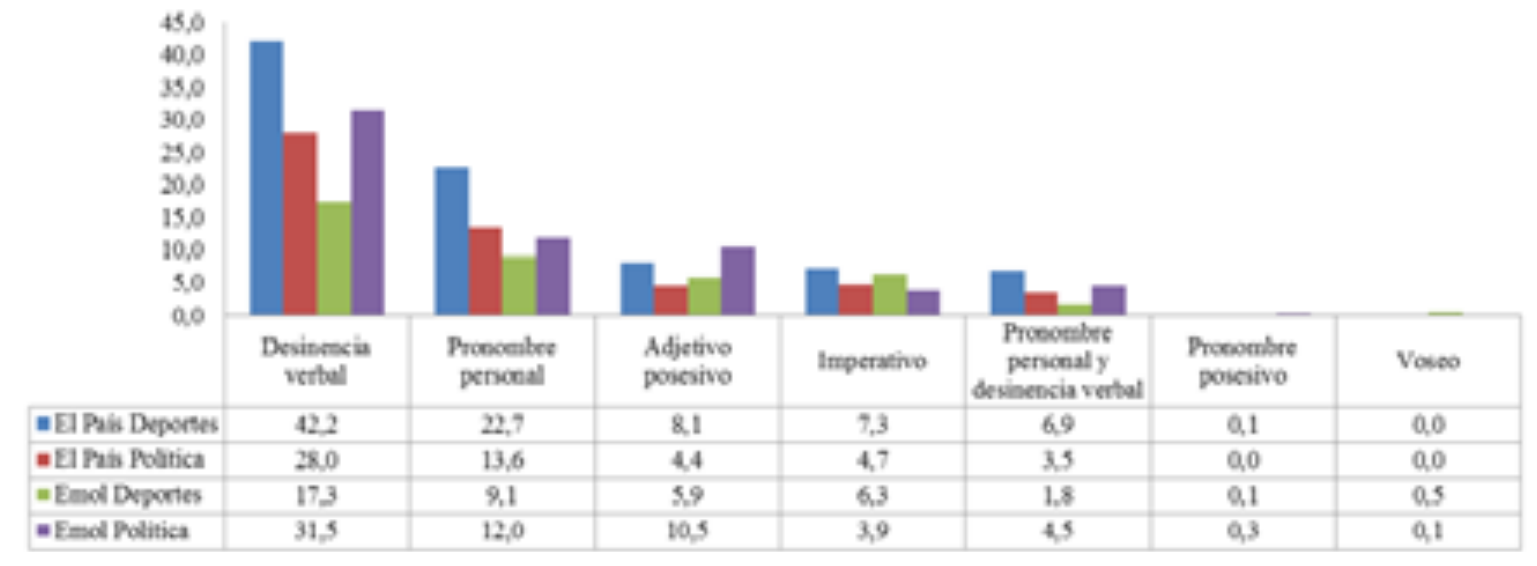

En esta categoría, el uso de la desinencia verbal también ha sido la subcategoría más frecuentemente utilizada como marcador de compromiso. Aunque no se halla entre las subcategorías más frecuentes, hemos de destacar el uso de verbos en la forma imperativa para explicar un acto de habla directo. 
También deseamos incidir en la escasa presencia de "voseo" en los comentarios digitales de Emol, ya que nos ha sorprendido, puesto que es un rasgo característico de la variedad chilena del español. El voseo es el uso de vos y/o sus formas verbales derivadas de la segunda persona singular; así, se distingue entre un voseo pronominal (uso simplemente del pronombre vos), un voseo verbal (uso de las desinencias verbales asociadas a un vos) o el uso de ambas. La morfología del voseo se corresponde con la segunda personal plural (vosotros) diptongadas, del tipo tomáis o coméis, pero también se encuentran formas monoptongadas, del tipo tomás o comés (propias del voseo rioplatense) o formas mixtas, como las de Chile, del tipo tomáis pero comís (Ramírez, 2007). Dentro de las diferentes formas de voseo que se pueden atestiguar en Latinoamérica, el voseo chileno es el que presenta una mayor extensión en relación con los tiempos y modos verbales (Rivadeneira y Clua, 2011). La presencia del voseo en Chile depende de si la situación de habla es más o menos formal; en otras palabras, se relaciona con el registro. De esta manera, a juicio de Rivadeneira y Clua (2011), en el registro informal se encontrarían tres tipos de voseo, según el tratamiento simétrico o no entre los participantes: i) tratamiento simétrico con uso de tú + voseo, que crea lazos de solidaridad y familiaridad entre los participantes; ii) tratamiento simétrico con voseo auténtico (es decir, vos + voseo), que cumple una función humorística; y iii) tratamiento asimétrico con uso de voseo auténtico, se origina en situaciones en las que existe una intención negativa donde se busca rebajar o disminuir la posición del oyente. Este último tratamiento tiene, por tanto, una connotación negativa dentro de la población. El uso del voseo en Chile está ampliamente generalizado (no al punto del voseo rioplatense), sobre todo en la lengua oral coloquial (Rivadeneira y Clua, 2011: 687).

Por ello, inicialmente esperábamos que los casos de "voseo" hubieran sido más frecuentes que los encontrados. Este hecho podría deberse a que los comentarios de noticias siguen perteneciendo al ámbito de la escritura, aunque en otras estrategias metadiscursivas se manifiesten rasgos propios de la oralidad. En ese sentido, la escritura es más conservadora que la oralidad y no admite fácilmente que se integren mecanismos de referencia asociados al registro oral. Este hecho nos lleva a reflexionar sobre la naturaleza del discurso digital, puesto que, si bien se ha indicado que presenta rasgos propios de la oralidad (tal como la entiende Briz, 2001) y, al mismo tiempo, se puede estudiar empleando mecanismos de análisis propios del español coloquial (o el análisis conversacional), en ciertos casos, como el que hemos observado en este artículo, no podemos estar de acuerdo con esta aseveración.

A continuación mostraremos en los ejemplos (3) y (4) el uso del "voseo" para transmitir un tono más directo e incluso violento como marcador de compromiso:

(3) A tan bajo costo?, dudo mucho que sea bajo ese costo por que gracias a Sampaoli vendimos en 4 palos a marcelo diaz que valia dos chauchas antes de el llegara, Gracias a la confianza que el profe le dio, ANgelo esta en el United y la U pudo cobrar 5 palos mas, gracias a Sampaoli, el negro 
Fernandez se fue pa Alemania, el que Sampaoli se nos vaya significa que dejaremos de percibir 7 palos verdes este año y a eso le llamai bajo costo, que otro entrenador ddel medio te genera todas esas utilidades? (emol_dep_19_17).

En este ejemplo, el uso del "voseo" chileno en estos contextos podría estar orientado no a reforzar vínculos con el resto de la audiencia, sino, por el contrario, a provocar el desacuerdo, aunque generalmente lo que desea es transmitir la actitud del comentarista (rabia) y despertar al lector, fomentando la réplica.

(4) no seai ridiculo... Mourinho para un equipo distinto para cada rival. 2 delanteros, 1 delantero, 2 jugadores por las bandas, 3 delanteros, triple 5, doble 5, un solo 5, q los laterales suban, que los laterales se queden pegados, sin organizador, con organizador por la banda... Y para que hablar del barcelona, 3 delanteros, 2 delanteros, 3 centrales, 2 centrales y 1 libero, 2 centrales y un lateral, 2 centrales y 2 laterales, doble 5 , un solo 5 , delanteros bien pegados por las bandas, delanteros que van por el centro, que el juego pase por messi, que messi solo llegue a definir... Asi es el futbol moderno, pero esta claro que no ves futbol... (emol_dep_06_02).

De la misma forma que en (3), el comentarista utiliza un tono agresivo en (4) para transmitir su malestar por lo que se ha comentado antes. Desea trasmitir proximidad con el lector mediante el uso del voseo pero marca una actitud negativa y defensiva respecto al lector.

Por otro lado, el empleo de la segunda persona singular formal usted marca una distancia entre el autor y el destinatario. Esta distancia puede resultar incluso mucho más efectiva que el uso del tú, puesto que no cabe duda de que la conversación se mantiene en el plano de la discusión de ideas y puntos de vista sin llegar a relacionarse con la misma persona. En este sentido, se establece como una marca de cortesía hacia el destinatario, como se muestra en (5) y (6):

(5) o sea me queda claro que ud, justifica el asesinato de este matrimonio, vaya!! con esos conceptos esta claro donde esta parado ud, y quienes son realmente los instigadores a la violencia y el odio en este pais, ud en Stgo siga respirando su smog, señor, ud no tiene idea de nada, no sabe nada, hay que estar en el lugar para podere opinar en consecuencia....y en todo caso, don Jorge no deja de tener razon, incluso esa misma declaracion en otros terminos la hizo hace unos años atras Perez-Yoma cuando fue ministro.....tierras productivas, ni una papa han sembrado hoy solo tristes potreros, bosques completos explotados y nunca reforrestados... digame donde estan los millones y millones de pesos recibidos por esos bosques??? en los lujos de los lideres y en armamento en mantener a gente que traen del extranjero para instigar a la violencia .....comentario racista....ja!! uds., siempre tienen de donde agarrarse aun con estupideces. (emol_pol_06_02)

(6) ¿Cuesta tanto ser un poco serio? A ver, usted pondría ante el Dortmund, uno de los equipos más fuertes de Europa, de lateral a un chico sin experiencia, que juega de central en el Castilla. Y a usted le hace mucha gracia las seis copas de Europa que ganó el Madrid en la época del blanco y 
negro. Pero en aquella época también existía el Barcelona, el Milán, el Inter, el Liverpool, etc, etc. Ninguno la ganó. La ganó el Madrid. Y claro, por eso son de risa. Un poco de seriedad, por favor. (elpaís_dep_17_23)

Cabe destacar el uso de la segunda persona plural informal en los comentarios de El País, que refleja el carácter cercano y solidario que tienen los comentarios de noticias. El tipo de interacciones que se fomenta con este uso implica un mayor compromiso con el receptor, como se ve en (7), en donde se pasa de hablar directamente a un tú, para luego referirse al grupo, al que se adscribe ese tú, a través de un vosotros, que genera una sensación de pertenencia a una colectividad:

(7) ¿Me has visto decir en algún momento que no quiero que se defienda, se proteja, se mime el catalán? La pregunta es: ¿tú crees que de verdad el catalán necesita ser más protegido de lo que ya está? Venga hombre. Me vienen a la cabeza las pequeñas tiendecitas de barrio a las que la Generalitat obligó hace años a cambiar el nombre del negocio si estaba en castellano. Sois vosotros los que acosáis al castellano allí, y no al contrario. Os creéis que habláis la lengua de los dioses. Puro aldeanismo. (elpaís_pol_13_09)

Hemos observado, al analizar el corpus, que las estrategias no se presentan de manera aislada, sino que se usan varios marcadores de compromiso con el objetivo de intensificar la adhesión que se busca conseguir por parte de la audiencia. En el ejemplo (8) se observa cómo el autor del comentario alude a la experiencia personal de su receptor y al mismo tiempo lo integra eficazmente dentro de su propio discurso, con el objetivo de que apoye los postulados del escritor.

(8) Parte importante de la vida universitaria es la formación social del estudiante y darse cuenta de que no somos seres individuales, sino que vivimos en una comunidad donde muchos sufren tu mismo problema. Boric no contamina a los estudiantes, sino que los alienta a organizarse y reclamar por su derecho a recibir una educación de calidad y a obligar al estado a financiarla, poniendo los dineros donde corresponde y no en manos de privados. Si tienes hijos o simplemente sentido social, deberías darte cuenta que en nuestra actual educación sólo estudia quien puede pagar. En caso contrario, quedas fuera o te adeudas. Soy profesora y apoyo el movimiento estudiantil, porque creo que nuestros jóvenes merecen una oportunidad y tenemos un estado que cuenta con los recursos y medios para otorgarla, sólo que a un grupo no le conviene, grupo al cual la gran mayoría de los chilenos no pertenecemos. Unámonos en esta causa y dejémonos de ofensas gratuitas, porque éste es un problema de TODOS (emol_pol_19_01).

Finalmente, comentaremos la tercera categoría más frecuente, "otras realizaciones", en la que se han agrupado todos aquellos elementos que se refieren directamente a los lectores bajo los paradigmas de conjugación y se han calculado las frecuencias normalizadas a 10.000. Hemos incluido el uso de vocativos, las preguntas retóricas y otros recursos que se originan 
por el carácter interactivo que se promueve en el discurso digital (despedidas o saludos), como se observa en detalle en la tabla 3:

\section{TABLA 3}

Frecuencias de "otras realizaciones"

\begin{tabular}{lllll} 
& EL PAIS & \multicolumn{1}{c}{ EMOL } & \\
\hline Deportes & Política & Deportes & Política \\
\hline Pregunta retórica & 5,2 & 6,2 & 20,9 & 27,3 \\
\hline Despedida & 35,9 & 29,3 & 20 & 19,7 \\
\hline Petición & 1 & 3 & 2,7 & 0,3 \\
\hline Agradecimiento & 0,8 & 0,3 & 2,5 & 2,4 \\
\hline Uno genérico & 0,3 & 0 & 0,7 & 0 \\
\hline Saludos & 2 & 2 & 0,5 & 1,7 \\
\hline
\end{tabular}

Destacamos de los resultados extraídos el uso de las pregunta retóricas como el recurso más empleado por todos los comentaristas, tanto los españoles como los chilenos, en los dos ámbitos, aunque se han encontrado más casos en El País en comparación con Emol. Las preguntas retóricas son un mecanismo que se utiliza para lograr la adhesión de la audiencia; este hecho lo han apuntado varios estudios sobre el metadiscurso (cf. Hyland, 2005a, 2005b; Mur-Dueñas, 2011; Li y Wharton, 2012). En el uso de las preguntas retóricas descansa uno de los rasgos dialógicos esenciales de la conversación; este permite estimular a los lectores e involucrarlos con sus ideas. Además, ellas cumplen la función de enfatizar la idea que está transmitiendo el autor, a la espera de despertar una respuesta de los destinatarios, tal como se ve en los ejemplos (9) y (10):

(9) Leonardo Y parq que chuchas querremos llegar a ser un pais desarrollado? Para empeñar nuestras vidas en el consumo y deudas a Cencosud, Falabella, Lider, etc, etc? Los unicos que gozaran las ventajas de tal desarrollo seran los dueños del capital, y no los giles que se desmadran para conseguir unas pocas chauchas para seguir consumiendo. No confundas hinchazon con gordura.Con este tipo de desarrollo mas bien es una involucion, donde volveremos a la esclavitud, pero esta vez, con cadenas hechas de tarjetas bancarias. (emol_pol_04_08)

(10) No estoy de acuerdo, en el mejor partido del Mundial España ganó a Alemania, que le había metido 4 a Argentina ¿no? y en la final a Holanda; no pudimos jugar contra Italia porque no fue capaz ni de ganar a Nueva Zelanda y se fue a casa "con vergonia" en la primera fase. ¿de que robo me hablas? Acaso Chile o Paraguay eran mejores que España? ¿Acaso no es España el mejor equipo ahora mismo? ¿Fue injusto que ganara el Mundial y la Eurocopa? mira, por tu forma acomplejada 
de hablar pensé que eras de un país centroamericano chungo, pero vienes de un país demasiado grande en todo como para que tengas tan mal perder y no admitas que ahora España es la mejor selección. España solo ganó ı-o muchos partidos porque Chile, Paraguay, Holanda, etc, montaron un autobús atrás, renunciaron al juego y se dedicaron a dar patadas; he visto los partidos varias veces (elpaís_dep_09_01).

La segunda subcategoría más frecuente en "otras realizaciones" es el uso de vocativos, que es más frecuente en Emol que en El País. Su uso como marcador de compromiso implica que son una posibilidad para involucrar y llamar la atención de los miembros de la audiencia, como se específica en el ejemplo (11). El uso de esta estrategia les confiere un tono personal a los comentarios digitales, que, en cierta manera, contradice la intención de invisibilidad del emisor y receptor del discurso digital:

(11) Yo tampoco estoy de acuerdo en que te borren los mensajes, es lo único en que coincido contigo. Me decías algo así como que "todo lo mío es anormal, como es anormal que perdone una infidelidad”. ¿Y qué es lo normal, Irene? ¿Lo que tú dices? ¿Lo que se aprende en la Iglesia? ¿Lo que redactan cuatro tíos machistas o represivos? ¿No ves que la "normalidad" es subjetiva y por tanto no se pueden emitir juicios de valor sobre asuntos morales? Mi pareja lleva años sacrificándose por mí. Ha renunciado a sus sueños por mí. Se deja la piel trabajando por nosotros. Incluso dejó su ciudad a $500 \mathrm{~km}$ para venir a mi lado. ¿Tú crees que todo ello queda anulado por una infidelidad? ¿Me creo tan especial como para que sea la única persona a la que ame en su vida? Absolutamente no. Eso es amor, Irene. Lo otro es puro instinto de posesión, de pertenencia. Y "amor" y "pertenencia” son dos conceptos que no se llevan bien. (elpaís_dep_09_21)

La diferencia en su uso por los españoles y chilenos puede estar relacionada con las características discursivas que han adoptado los usuarios para adaptarse al entorno tecnológico. El hecho de que en Emol se emplee Facebook para comentar provoca que las interacciones se desarrollen tal como los usuarios se comportan en dicha red social, y ello influye en el uso de ciertos marcadores metadiscursivos. A continuación pasamos a concluir el estudio que hemos llevado a cabo y a contestar las preguntas de investigación.

\section{Conclusiones}

En este estudio primero deseamos destacar que se han encontrado más casos de marcadores de compromiso en los comentarios digitales de noticias que en otros estudios, como, por ejemplo, los realizados sobre el discurso académico. Este hallazgo reafirma la idea de que el uso de los marcadores de compromiso está influido por el contexto situacional. Asimismo, el etiquetado llevado a cabo de los elementos que actúan como marcadores de compromiso se ha basado en las propuestas de Hyland (2005a), Mur-Dueñas (2008, 2011), Fu y Hyland (2014) y Hyland y Jiang (2016), con lo cual hemos utilizado una taxonomía integradora. 
En lo que respecta a la hipótesis de partida, hemos de indicar que se refuta, puesto que existe variación estadísticamente relevante en el uso de los marcadores de compromiso. Respecto a nuestro objetivo, la variación es menor que la que esperábamos encontrar inicialmente, pero tras el estudio de los resultados pormenorizados por categorías podemos afirmar que las estrategias de compromiso son utilizadas de forma distinta por los españoles y chilenos.

Respondiendo a las preguntas de investigación de este análisis, la estrategia más utilizada por los comentaristas, tanto chilenos como españoles, para captar la atención de los lectores e incluirlos como participantes del discurso digital ha sido la categoría "primera persona plural inclusiva". Los comentarios incluidos en Emol por comentaristas chilenos fueron los que más utilizaron esta estrategia discursiva. Los ámbitos temáticos no marcaron una gran diferencia en los resultados de esta categoría, ya que en El País se encontraron más casos en política que en deportes mientras que en Emo/ se encontraron más casos en deportes que en política.

La segunda estrategia utilizada fue la categoría del uso de la segunda persona singular, que integra al lector al dirigirse el comentarista directamente a él. En este caso, se encontraron más casos en El País de esta estrategia integradora. Los resultados de los temas de los comentarios tampoco nos permitieron detectar una variación en el uso, ya que son dispares. Por lo tanto, podemos concluir que las variedades de la lengua influyen en la elección de los marcadores de compromiso, mientras que los ámbitos temáticos, la política y los deportes, no influyeron en la elección de esas estrategias metadiscursivas.

Finalmente deseamos destacar que las características de los comentarios en la prensa digital, tales como el sentido de inmediatez, la invisibilidad del emisor y receptor, la capacidad de reflexión antes de participar y la comunicación asíncrona y móvil, modifican, efectivamente, la elección de los marcadores de compromiso por parte de los comentaristas. Lo afirmamos puesto que se prefieren marcadores que integren a los lectores en el discurso, pero sin renunciar a la identidad del escritor, aunque también se trata de evitar la invisibilidad del receptor con el uso de la segunda persona singular. Este hecho creemos que se debe al tipo de discurso analizado, ya que el comentarista ha de comprometer al lector en su discurso para provocar la lectura y comentarios a sus opiniones.

\section{Bibliografía citada}

Abdollahzadeh, Esmaeel, 2011: "Poring over the findings: Interpersonal authorial engagement in applied linguistics papers", Journal of Pragmatics 43, 288-297.

Acebedo Restrepo, Juan Carlos, 2013: "The Political Insult in Online Discussion Forums of Readers of the Colombian Digital Press", Signo y Pensamiento 32 (62), 48-63. 
Alonso Almeida, Francisco, y María Luisa Carrió-Pastor, 2015: "Sobre la categorización de seem en inglés y su traducción en español. Análisis de un corpus paralelo", Revista Signos $48(88), 154-173$.

Arancibia, Cristina, y Lésmer Montecino, 2013: "El blog de comentarios de textos de opinión en ciberperiódicos: un género en constante reconstrucción”, Literatura y Lingüística 28, 123-147.

Briz, Antonio, 2001: El español coloquial en la conversación: esbozo de pragmagramática, Barcelona: Ariel.

BRUCE, Ian, 2011: "Evolving genres in online domains: The hybrid genre of the participatory news article" en Alexander Mehler, Serge Sharoff y Marina Santini (eds.): Genres on the Web, Amsterdam: Springer, 323-348.

Carrió-Pastor, María Luisa, y Ruth Muñiz Calderón, 2013: "Variation of English business e-mails in Asian countries", Ibérica 26, 55-76.

Carrió-Pastor, María Luisa, y Ruth Muñiz Calderón, 2015a: "A contrastive analysis of metadiscourse features in business e-mails written by non-native speakers of English", Procedia-Social and Behavioral Sciences 173, 214-221.

Carrió-Pastor, María luisa, y Ruth Muñiz Calderón, 2015b: "Identification and causes of lexical variation in Chinese Business English”, English Today 31, 10-15.

Carrió-Pastor, María Luisa, 2016: "A contrastive study of interactive metadiscourse in academic papers written in English and in Spanish" en Francisco Alonso Almeida, Laura Cruz García y Víctor Gonzalez Ruiz (eds.): Corpus-based studies on language varieties, Berna: Peter Lang.

Cebrián Herreros, Mariano, 2009: "Comunicación interactiva en los cibermedios”, Comunicar 33, $15-24$.

Fu, Xiaoli, y Ken HyLAND, 2014: "Interaction in two journalistic genres. A study of interactional metadiscourse”, English Text Construction 7 (1), 122-144.

GonzAlez Arias, Cristian, y Laura López, 2013: "Las expresiones agresivas en los comentarios de los usuarios de blogs periodísticos: un análisis por medio de la teoría de la valoración”, Tonos Digita/ 24 [disponible en http://www.um.es/tonosdigital/znum24/ secciones/estudios-15-_expresiones_agresivas_en_blogs.htm, fecha de consulta: 9/11/2016].

GonzÁlez Arias, Cristian, 2014: "El metadiscurso en columnas de opinión y en los comentarios de lectores en un ambiente virtual y público", Spanish in Context 11 (2), 155-174.

HerRING, Susan, y Bernie Demarest, 2011: "Mode choice in multimodal comment threads: Effects on participation and language use". Manuscrito inédito. 
Herring, Susan, 2013: "Discourse in Web 2.0: Familiar, reconfigured, and emergent" en Deborah TANnen y Anna Marie Trester (eds.): Discourse 2.0, Georgetown: Georgetown University Press, 1-25.

HYLAND, Ken, y Feng JIANG, 2016: “'We must conclude that....: A diachronic study of academic engagement", Journal of English for Academic Purposes 24, 29-42.

HyLAND, Ken, y Polly Tse, 2004: "Metadiscourse in Academic Writing: A Reappraisal", Applied Linguistics 25 (2), 156-177.

Hyland, Ken, 2005a: Metadiscourse: Exploring Interaction in Writing, Londres: Continuum International Publishing Group.

HyLand, Ken, 2005b: "Stance and engagement: a model of interaction in academic discourse", Discourse Studies, 7 (2), 173-192.

JiAnG, Kevin, y Ken HyLAND, 2016: "Nouns and academic interactions: A neglected feature of metadiscourse", Applied Linguistics, amw023 [disponible en https://doi.org/10.1093/applin/ amw023].

LAfUente-Millán, Enrique, 2014: "Reader engagement across cultures, languages and contexts of publication in business research articles", International Journal of Applied Linguistics 24 (2), 201-223.

LI, Ting, y Sue WHARTON, 2012: "Metadiscourse repertoire of L1 Mandarin undergraduates writing in English: A cross-contextual”, Journal of English for Academic Purposes 11, 345-356.

Mancera Rueda, Ana, y Ana Pano Alamán, 2013: El discurso político en Twitter, Barcelona: Anthropos.

Mancera Rueda, Ana, 2009: "Manifestaciones de descortesía y violencia verbal en los foros de opinión digitales de los diarios españoles”, Discurso \& Sociedad 3 (3), 437-466.

Martinrey, Guiomar, y Vicente Serrano Marín, 2011: "Periodismo ciudadano y espacio público en la Sociedad de la Información”, Anàlisi: quaderns de comunicació i cultura 41, 69-85.

Meso, Koldobika, 2013: "Periodismo y audiencias: inquietudes sobre los contenidos generados por los usuarios”, Cuadernos.info 33, 63-73.

Montecino, Lésmer, y María Cristina AranciBia, 2015: "Recursos de valoración en comentarios de blogs de ciberperiódicos chilenos: representaciones discursivas sobre crecimiento, desigualdad y justicia social", Boletín de filología 50 (2), 77-101.

Montero-Fleta, Begoña, Anna Montesinos-López, Carmen Pérez-Sabater y Edward Turney, 2009: “Computer mediated communication and informalization of discourse: The influence of culture and subject matter", Journal of Pragmatics 41 (4), 770-779. 
Moya Muñoz, Patricio, 2015: "Los comentarios de los usuarios en la prensa digital: una propuesta para su estudio desde el discurso mediado por ordenador y los estudios periodísticos", Caracteres 4 (1), 178-199.

Mur-Dueñas, Pilar, 2011: "An intercultural analysis of metadiscourse features in research articles written in English and in Spanish”, Journal of Pragmatics 43 (12), 3068-3079.

Mur-Dueñas, Pilar, 2008: "Analysing engagement markers cross-culturally: The case of English and Spanish business management research articles" en Sally BuRgess y Pedro Martín Martín (eds.): English as an additional language in research publication and communication, Berna: Peterlang, 197-214.

O’DonnelL, Mick, 2013: UAM Corpus Tool (versión 3.1.12), Madrid: Universidad Autónoma de Madrid.

Pano Alamán, Ana, 2012: "Diálogo e información conversacional en la prensa digital española" en Alessandro Cassol, Flavia Gherardi, Augusto Guarino, Giovanna Mapelli, Francisco Matte Bon, Pietro Taravacc (eds.): Il dialogo, Lingue, letterature, linguaggi, culture, Roma: Aispi Edizioni, 351-358.

Pano Alamán, Ana, 2013: "Fronteras abiertas entre lo escrito y lo oral: Ia cita en los comentarios a las noticias en la prensa digital" en María Victoria Calvi, Antonella Cancellier y Elena Liverani (eds.): Frontiere: soglie e interazioni. I linguaggi ispanici nella tradizione en ella contemporaneità, Trento: Quaderni del Dipartimento di Lettere e Filosofia, 295-311.

Pastor, Lluís, y Silvia Martínez-Martínez, 2013: "La retórica al servicio del usuario: estudio de los comentarios de los lectores en Elpaís.com, Abc.es y Lavanguardia.es”, El profesional de la información 22 (2), 113-121.

Peterlin, Agnes, 2016: "Engagement markers in translated academic texts", English Text Construction 9 (29), 268-291.

Ramírez, José Luis, 2007: Breve Historia del español en América, Madrid: Arco Libros.

Rivadeneira, Marcela, y Esteve Clua, 2011: "El voseo chileno: una visión desde el análisis de la variación dialectal y funcional en medios de comunicación”, Hispania 94 (4), 680-703.

Ruiz, Carlos, David Domingo, Josep Micó, Javier Diaz-Noci, Koldo Meso y Pere Masip, 2011: "Public Sphere 2.0? The Democratic Qualities of Citizen Debates in Online Newspapers", The International Journal of Press/Politics 16, 463-487.

Ruiz, Carlos, Pere Masip, Josep Mıcó, Javier Díaz-Nocı, David Domingo, 2010: "Conversación 2.0 y democracia. Análisis de los comentarios de los lectores en la prensa digital catalana”, Comunicación y Sociedad 23 (2), 7-39. 
SAL PAZ, Julio, 2013: "Comentario digital: género medular de las prácticas discursivas de la cibercultura”, Caracteres 152-171.

SAL PAZ, Julio, 2016: "El comentario digital como género discursivo periodístico. Análisis de La Gaceta de Tucumán”, Aposta 69, 158-216.

SuAu-Jiménez, Francisca, 2014: "Dialogic voices of writers and readers in travellers' forums through interpersonality" en Luz GIL-Salóm y Carmen Soler-Monreal (eds.): Dialogicity in Written Specialised Genres, Amsterdam: John Benjamins Publishing, 137-164.

TAKI, Saeed, y Fatemeh JAFARPOUR, 2012: "Engagement and stance in academic writing: A study of English and Persian research articles", Mediterranean Journal of Social Sciences 3 (1), 157-168.

Thurlow, Crispin, y Kristine Mroczek, 2011: "Introduction: Fresh perspectives on new media sociolinguistics", Digital discourse: Language in the new media, Oxford: Oxford University Press, xix-xliv.

WILES, Roy, 1965: Freshest advices, Ohio: Ohio State University Press. 